\title{
Hazard Identification, Risk Assessment and Risk Control (HIRARC) Accidents at Power Plant
}

\author{
Asmalia Che Ahmad ${ }^{1 a}$, Ida Nianti Mohd Zin ${ }^{1}$, Muhammad Kamil Othman ${ }^{1}$, Nurul Huda Muhamad ${ }^{1}$ \\ ${ }^{1}$ Faculty of Architecture, Planning and Surveying, Universiti Teknologi Mara (Perak), Seri Iskandar, Malaysia
}

\begin{abstract}
Power plant had a reputation of being one of the most hazardous workplace environments. Workers in the power plant face many safety risks due to the nature of the job. Although power plants are safer nowadays since the industry has urged the employer to improve their employees' safety, the employees still stumble upon many hazards thus accidents at workplace. The aim of the present study is to investigate work related accidents at power plants based on HIRARC (Hazard Identification, Risk Assessment and Risk Control) process. The data were collected at two coal-fired power plant located in Malaysia. The finding of the study identified hazards and assess risk relate to accidents occurred at the power plants. The finding of the study suggested the possible control measures and corrective actions to reduce or eliminate the risk that can be used by power plant in preventing accidents from occurred
\end{abstract}

\section{Introduction}

Power plant is a place to generate energy of electricity for millions of household and industries. There are many types of power plant all over the world such as gas turbine power plant, steam turbine power plant, fossilfuel power plant, nuclear power plant, and hydro power plant.

Power plant is a workplace of the high level from hazard, where safe working procedures are important as workers face many risks due to the nature of the job. The work environment is often hot and noisy, consist several major equipment and operations involve in its process, and there is an always present risk for crushing injuries, electrical shocks and burns, boiler fires and explosions, and contact with hazardous chemicals. Figures from International Labour Organization (ILO) (2014)[1] showed that more than 2.3 million deaths per year are recorded. This shows that accident happen every 15 second a worker dies from work related to accident or illness. Moreover, at every 15 seconds 160 workers have accidents. That means 6300 people die as results of working accidents or work diseases every day. Due to the hazardous operation of power plant, this workplace is exposed to accident and near miss incidents (Cohen and Colligan, 1998). In addition, OECD (2008) [2] reported that more than 2500 people are killed every year in energy related plant with severe accidents. This number appears to be rising as energy usage continues to increase every year. Between 1969 and 2000, there were 1870 such accidents with five fatalities. The largest number of immediate fatalities in the fossil energy chains was in coal and oil, i.e. 2259 and 3713 respectively and in OECD countries, and 18017 and 16505 respectively in non-OECD countries. Table 1 summarises the severe accidents in the fossil, hydro and nuclear energy chains in the period of 1969-2000.

Due to the risky workplaces that power plants constitute, the companies need to assure safe working conditions through systematic and regular hazard identification and risk assessment. Safety procedures and regulations need to be followed by the management as well as the workers. Many business enterprises have proven that good safety management leads to increased productivity, and the same works for power plant. By having a good safety management program, not only minor injuries can be avoided, but also other incidents that are costly, time consuming, stressful and inconvenient. Due to this reason for reduction of all occupational diseases, injuries/fatalities, corrective and preventive measure should be done. OHSAS 18001:2007 (clause 4.3.1), suggested that a safety procedure is a must to ensure the identification of hazard, risk assessment, and its determination to eliminate, reduce or control the possibility for any accidents to occur. Thus, this paper highlights report on hazard identification, risk assessment and risk control applied in the coal-fired power plant located in Malaysia. It includes the methodological steps to identify hazard, assess the risk level of the hazards and apply or suggest the possible control measures and corrective actions to reduce or eliminate the risk.

Table 1: Summary of manmade energy related power plant accidents for the period of 1969-2000 [1]

\footnotetext{
a Corresponding author: asmalia809@perak.uitm.edu.my
} 


\begin{tabular}{|l|r|r|c|c|c|c|}
\hline & \multicolumn{3}{|c|}{ OECD } & \multicolumn{3}{|c|}{ Non-0ECD } \\
\hline $\begin{array}{l}\text { Energy } \\
\text { chain }\end{array}$ & Accidents & Fatalities & $\begin{array}{c}\text { Fatalitiesl } \\
\text { GWey }\end{array}$ & Accidents & Fatalities & $\begin{array}{c}\text { Fatalitiesi } \\
\text { GWey }\end{array}$ \\
\hline Coal & 75 & 2259 & 0.157 & 1044 & 18017 & 0.597 \\
\hline $\begin{array}{l}\text { Coal (data } \\
\text { for China } \\
\text { 1994-1999) }\end{array}$ & \multicolumn{7}{|c|}{} & 819 & 11334 & 6.169 \\
\hline $\begin{array}{l}\text { Coal (without } \\
\text { China) }\end{array}$ & \multicolumn{7}{|c|}{} & 102 & 4831 & 0.597 \\
\hline Oil & 165 & 3713 & 0.132 & 232 & 16505 & 0.897 \\
\hline Natural Gas & 90 & 1043 & 0.085 & 45 & 1000 & 0.111 \\
\hline LPG & 59 & 1905 & 1.957 & 46 & 2016 & 14.896 \\
\hline Hydro & 1 & 14 & 0.003 & 10 & 29924 & 10.285 \\
\hline Nuclear & 0 & 0 & - & 1 & $31^{*}$ & 0.048 \\
\hline Total & 390 & 8934 & & 1480 & 72324 & \\
\hline
\end{tabular}

\section{Accidents at Power Plant}

An accident is defined as an unfortunate that happens unpredictably and inadvertently, resulting in harm or injury [2]. The accident occurs depending on the situations, either results in minor fatalities or have the potential for but do not result in a loss [3]. Accidents are more usually related with event on site leading to adverse significances for the establishments like leaks, fire and explosions [4]. In another study, [5] found that injury rates are contrast with business cycle which means when economic sector increases, the number of injuries will increase too and vice versa. [6] relate injury rates to structural effects such as workers characteristic, firm size, production process, types of industry and types of occupation.

\section{HIRARC}

In recent years, Hazard Identification, Risk Assessment and Risk Control (HIRARC) have become fundamental to the practice of planning, management and the operation of a business as a basic of risk management. A hazard identification and risk assessment are processes used to identify and evaluate both existing and potential hazards on a worksite and the methods used to control or eliminate the hazards identified. The organizations that have carried out risk assessment at the work place have noted numerous changes in their working practice. Those who have already carried out risk assessment in their work, have reported positive changes in their working practice, they recognize substandard act and working condition as they develop and take necessary corrective action. Legislation requires that this process should be systematic and be recorded so that the results are reliable and the analysis complete. The risk assessment process should be continuous and should not be regarded as a one-off exercise.

\subsection{Hazard identification}

Hazard is defined as anything (e.g. condition, situation, practice, behaviour) that has the potential to cause harm, including injury, disease, death, environmental, property and equipment damage. This is the process of examining each work area and work task for the purpose of identifying all the hazards which are "inherent in the job".

\subsection{Risk Assessment}

Hazard is closed relationship with the risk. Risk is a measurement to analyse and evaluate the hazard [7]. The measurement is made by identification on how severe and when likely of the hazard. In other words, the risk assessment is an in-depth look to specify situations, process and other harmful activities or hazard at workplace. Risk is presented in variety of ways to communicate the distribution of the risk throughout a plant and area in a workplace. The results of risk assessment that presented in a risk matrix are essential to make decision on risk control.

Risk can be calculated using the following formula [7]: Risk $(\mathrm{R})=$ Likelihood (L) $x$ Severity $(\mathrm{S})$

In order to determine the risk level, the risk assessment matrix has to be resolve. The computations of the risk assessment matrix in order to attain the risk level consist of following steps:

1. Calculation of weightage average index (WAI) for likelihood of hazards

2. Calculation of weightage average index (WAI) for severity of hazards

3. Calculation of risk (WAI likelihood x WAI severity) of hazard

4. Determination of risk assessment matrix (Table 2) and risk level (Table 3)

The weightage average index is calculated based on the formula as below [7] :

Weightage Average Index $(\mathrm{WAI})=\sum \frac{\text { wi fi }}{\sum \mathrm{fi}}$ where:

wi $=$ assigned weight for a particular class under 5-point likert scale

fi = corresponding frequency of that particular class

$\mathrm{i}=1,2,3,4,5$ that illustrated 5-point likert scale according to specific context

The computation of WAI for each hazard was interpreted by schedule of risk assessment matrix (Table 2) and the indication of risk level in Table 3. Then result from calculation of risk assessment was referred to scale of risk level.

Table 2: Risk Assessment Matrix level [7]

\begin{tabular}{|l|c|c|c|c|c|}
\hline \multirow{2}{*}{$\begin{array}{l}\text { LIKELIHOOD } \\
\text { OF HAZARDS }\end{array}$} & \multicolumn{5}{|c|}{ SEVERITY OF HAZARDS } \\
\cline { 2 - 6 } & $\begin{array}{c}\text { INSIGNI } \\
\text { FICANT }\end{array}$ & $\begin{array}{c}\text { MINOR } \\
(2)\end{array}$ & $\begin{array}{c}\text { MODE } \\
\text { RATE } \\
(3)\end{array}$ & $\begin{array}{c}\text { MAJOR } \\
(4)\end{array}$ & $\begin{array}{c}\text { FATAL } \\
(5)\end{array}$ \\
\hline RARE (1) & 1 & 2 & 3 & 4 & 5 \\
\hline UNLIKELY (2) & 2 & 4 & 6 & 8 & 10 \\
\hline POSSIBLE (3) & 3 & 6 & 9 & 12 & 15 \\
\hline LIKELY (4) & 4 & 8 & 12 & 16 & 20 \\
\hline $\begin{array}{l}\text { ALMOST } \\
\text { CERTAIN (5) }\end{array}$ & 5 & 10 & 15 & 20 & 25 \\
\hline
\end{tabular}


Table 3. Indication of risk level [15].

\begin{tabular}{|c|c|}
\hline \multicolumn{2}{|c|}{ RISK LEVEL } \\
\hline 1 to 2 & LOW \\
\hline 3 to 6 & MEDIUM \\
\hline 7 to 12 & HIGH \\
\hline More than 12 & EXTREME \\
\hline
\end{tabular}

The purpose of hazard identification and risk assessment in this study is to highlight the critical operations of tasks that poses significant risks to the health and safety of employees as well as highlighting those hazards pertaining to certain equipment due to energy sources, working conditions or activities performed. Then risk level is assigned to each hazard for identifying required corrective action to minimize the risk or eliminate the hazard. This study was conducted according to basic of safety procedure which is hazard identification and risk survey in order to assess the risk in the plant.

\subsection{Risk Control}

Risk control is the elimination or inactivation of hazard in a manner such that the hazard does not pose a risk to workers. Hazards should be controlled at their source where the problem is created. Venturini (2011) rating four characteristics of risk that are commonly identified (refer Table 4), according to the measures taken to protect the plant from risk exposure are:

i. Excellent: the facility has taken measures exceeding industry standards and the best practices. Loss potential is considered significantly reduced.

ii. Good: the fatality has taken measures that are consistent with industry standards and best practices. Loss potential is considered to be average.

iii. Fair: the fatality has taken some measures that approach industry standards and best practices, however deficiencies exist. Loss potential is considered somewhat increased. iv. Poor: the fatality has major deficiencies and does not approach industry standards and best practices. Loss potential is considered to be significantly increased.

\section{Research Methodology}

To further investigate the hazard identification, risk assessment and risk control applied in the power plant, this study adopted questionnaire survey and interviews for data collection. The data were collected in two (2) coal-fired power plants. A total of 50 questionnaires were sent. Within the collected questionnaires, 17 forms were uncompleted and were thus disregarded, while 30 forms were completed. Two accident cases at power plant were analyzed. The name and location of the power plant cannot be exposed due to the private and confidentiality. Data obtained by the questionnaire and personal interview was subjected to quantitative analysis. The percentage was calculated by simple mathematical formulas. The data from the questionnaire survey were analysed using Excel to compose weightage average index (WAI) in order to compute the risk level of those hazards. Semi-structured interviews with 30 employees were used to gather perceptions regarding the situation of safety at their workplace.

Table 5 shows that $16(53 \%)$ of the respondents who participated in this study were engineers, $4(13 \%)$ were project managers, and $5(17 \%)$ were technician and general workers accordingly. The range of personal experience of the respondents in terms of number of years involved or worked in power plant between 1 to more than 20 years as indicated in Table 6. More than half $(46.67 \%)$ of respondents have more than 15 years experience. Whilst, $23 \%$ of the respondents have more than 10 years working experience and are all familiar with the main issues surrounding safety at their workplace.

Table 4: Control Measure Matrix

\begin{tabular}{|l|l|l|}
\hline \multicolumn{1}{|c|}{ CONTROL MEASURES } & \multicolumn{2}{c|}{ LEVEL } \\
\hline $\begin{array}{l}\text { Control measures exceeding industry standards and the best } \\
\text { practices. Loss potential is considered significantly reduced }\end{array}$ & Excellent & $3.1-4.0$ \\
\hline $\begin{array}{l}\text { Control measures that are consistent with industry standards } \\
\text { and best practices. Loss potential is considered to be average }\end{array}$ & Good & $2.1-3.0$ \\
\hline $\begin{array}{l}\text { Control measures that approach industry standards and best } \\
\text { practices, however deficiencies exist. Loss potential is } \\
\text { considered somewhat increased }\end{array}$ & Fair & $1.1-2.0$ \\
\hline $\begin{array}{l}\text { A control measure has major deficiencies and does not } \\
\text { approach industry standards and best practices. Loss potential } \\
\text { is considered to be significantly increased. }\end{array}$ & Poof & $0-1.0$ \\
\hline
\end{tabular}


Table 5 Current job title/position of the respondents for the two selected coal-fired power plant.

\begin{tabular}{|c|c|c|}
\hline Job position & Frequency & Percentage $\%$ \\
\hline Project manager & 4 & 13 \\
\hline Engineer & 16 & 53 \\
\hline Technician & 5 & 17 \\
\hline General workers & 5 & 17 \\
\hline Total & 30 & 100 \\
\hline
\end{tabular}

Table 6 : Length of time involved/worked in the power plant

\begin{tabular}{|c|c|c|}
\hline $\begin{array}{c}\text { Working } \\
\text { experience with } \\
\text { power plant }\end{array}$ & Frequency & Percentage $\%$ \\
\hline $1-5$ & 6 & 20 \\
\hline $5-10$ & 3 & 10 \\
\hline $11-15$ & 8 & 23.33 \\
\hline $16-20$ & 9 & 30 \\
\hline$>20$ & 5 & 16.67 \\
\hline Total & 30 & 100 \\
\hline
\end{tabular}

As can be seen from the Table $5 \&$ Table 6 , it can be conclude that the respondents who answered the questionnaires and interviews are those have enough knowledge about the safety at their workplaces; with extensive working experiences and those holding responsible positions in the power plants. Their answers to the questionnaires and interviews give a high level of credibility in terms of their opinions regarding the issues raised.

\section{Case Study}

The study involved two coal-fired power plants that were established to meet the anticipated growth in electricity demand, and help maintain the required power reserve margin. The design, development and management of the power plant, in line with national strategy to produce heavy dependence on natural gas as fuel source for power generation. It is designed to operate within minimizing power plant impact on the environment.

\subsection{Report on Accident Case 1}

Accident 1 occurred at shoreline access road. The type of accident is classified property damage. Nature of injury is right knee swollen. The victim of the accident is a general worker and has 3 years experience. The accident also has one witness from the department at the accident location. Table 7 shows the WAI likelihood, WAI severity and risk assessment matrix for the four identified hazard. Four hazards have been identified in accident case 1 as per list follow below:

1) No inspection on rented machinery.

2) Misunderstanding of communication with security staff.

3) Rented forklift driver without competency certification.

4) No HIRAC on scrap disposal activity.

The risk was calculated by multiplying likelihood with severity. Each figure of the risk was categorised into risk level and rank accordingly. Out of four types of hazards identified, 2 hazards were classified under extreme risk while another two were in high risk. None of the hazards falls in either medium or low risk level.

Table 7: Summary of hazards identification, risk assessement, and control measure for Case 1.

\begin{tabular}{|c|c|c|c|c|c|c|c|c|}
\hline \multirow{2}{*}{ NO. } & \multirow{2}{*}{$\begin{array}{c}\text { HAZARD } \\
\text { IDENTIFICATION } \\
\text { CASE } 1\end{array}$} & \multicolumn{4}{|c|}{ RISK ASSESSMENT } & \multirow{2}{*}{ RANK } & \multirow[t]{2}{*}{ CONTROL MEASURES } & \multirow[t]{2}{*}{ Level } \\
\hline & & $\begin{array}{l}\text { HOOD } \\
\text { (MEAN) }\end{array}$ & $\begin{array}{l}\text { SEVERITY } \\
\text { (MEAN) }\end{array}$ & RISK & RISK LEVEL & & & \\
\hline 1 & $\begin{array}{l}\text { No inspection on rented } \\
\text { machinery. }\end{array}$ & 5.00 & 2.17 & 10.87 & High & 3 & $\begin{array}{l}\text { Brief security on the procedure } \\
\text { requirement regarding rented forklift } \\
\text { and machinery inspection. }\end{array}$ & Excellent \\
\hline 2 & $\begin{array}{l}\text { Misunderstanding of } \\
\text { communication with security } \\
\text { staff. }\end{array}$ & 4.80 & 2.14 & 10.27 & High & 4 & $\begin{array}{l}\text { Review procedure for forklift } \\
\text { operation certification and operating } \\
\text { to include vehicle inspection }\end{array}$ & Good \\
\hline 3 & $\begin{array}{l}\text { Rented forklift driver } \\
\text { without competency } \\
\text { certification. }\end{array}$ & 4.60 & 2.85 & 13.10 & Extreme & 2 & $\begin{array}{l}\text { Brief security on the correct way of } \\
\text { using walkie-talkie. }\end{array}$ & Excellent \\
\hline 4 & $\begin{array}{l}\text { No HIRAC on scrap } \\
\text { disposal activity. }\end{array}$ & 4.93 & 2.70 & 13.30 & Extreme & 1 & $\begin{array}{l}\text { Prepare HIRAC for scrap disposal } \\
\text { activity. }\end{array}$ & Excellent \\
\hline
\end{tabular}




\subsection{Report on Accident Case 2}

Accident 2 occurred at combustion chamber Gas Turbine. The type of accident is classified medical treatment injury. Nature of injury is hit by falling burner at the back of right hand. The victim of the accident is a man as a general worker and has no experience. The accident also has one witness from the department at the accident location. Five (5) hazards at power plant were identified in accident number 2 as per list follow below:

1) Two different works was performed at same time.

2) Working space constrained.

3) Design and setting up on equipment is not proper.

4) No inspection checklist on the bucket prior use.

5) Lack of precaution on this activity.

All five types of hazards identified were classified under high risk. None of the hazards falls in extreme risk level (Table 8).

\section{Conclusion}

In this paper we investigate and describe work related accidents at power plants based on HIRARC (Hazard Identification, Risk Assessment and Risk Control) process. The risk ranking of the present and possible hazard is evaluated which divide them into low, medium, high and extreme risk level. Which risks are in high and extreme level there possible corrective action also recommended for risk control. Power plant need to assess the risk not only for the risk and control measures but it will conducted for cost if occurred accidents and near miss incidents at power plant. Hazard identification, risk assessment and control is an on-going process. Therefore, regularly review the effectiveness of hazard assessment and control measures is needed.

Table 8: Summary of hazards identification, risk assessement, and control measure for Case 2.

\begin{tabular}{|c|c|c|c|c|c|c|c|c|}
\hline \multirow{2}{*}{ NO } & \multirow{2}{*}{$\begin{array}{c}\text { HAZARD IDENTIFICATION } \\
\text { CASE } 2\end{array}$} & \multicolumn{4}{|c|}{ RISK ASSESSMENT } & \multirow[t]{2}{*}{ RANK } & \multirow[t]{2}{*}{$\begin{array}{l}\text { CONTROL } \\
\text { MEASURES }\end{array}$} & \multirow[t]{2}{*}{ Level } \\
\hline & & $\begin{array}{l}\text { LIKELI- } \\
\text { HOOD } \\
\text { (MEAN) }\end{array}$ & $\begin{array}{l}\text { SEVERITY } \\
\text { (MEAN) }\end{array}$ & RISK & $\begin{array}{l}\text { RISK } \\
\text { LEVEL }\end{array}$ & & & \\
\hline 1 & $\begin{array}{l}\text { Two different works was } \\
\text { performed at same time. }\end{array}$ & 4.00 & 3.00 & 12.00 & HIGH & 4 & $\begin{array}{l}\text { Check the bucket } \\
\text { floor and increase } \\
\text { height of the floor } \\
\text { guard }\end{array}$ & Excellent \\
\hline 2 & Working space constrained & 4.30 & 3.42 & 14.70 & HIGH & 1 & $\begin{array}{l}\text { Install extra } \\
\text { plywood guard in } \\
\text { the middle of the } \\
\text { bucket }\end{array}$ & Excellent \\
\hline 3 & $\begin{array}{l}\text { Design and setting up on } \\
\text { equipment is not proper. }\end{array}$ & 3.70 & 3.72 & 13.77 & HIGH & 2 & $\begin{array}{l}\text { Inspection before } \\
\text { start the inspection } \\
\text { must be done }\end{array}$ & Excellent \\
\hline 4 & $\begin{array}{l}\text { No inspection checklist on the } \\
\text { bucket prior use. }\end{array}$ & 4.50 & 2.40 & 10.80 & HIGH & 5 & $\begin{array}{l}\text { Bucket to be placed } \\
\text { on the split line area } \\
\text { for every inspection } \\
\text { work to ensure the } \\
\text { stability and reduce } \\
\text { impact from bucket } \\
\text { or burner if fall }\end{array}$ & Excellent \\
\hline 5 & $\begin{array}{l}\text { Lack of precaution on cycle of } \\
\text { removing burner at combustion } \\
\text { chamber. }\end{array}$ & 3.90 & 3.20 & 12.50 & HIGH & 3 & $\begin{array}{l}\text { Supervision to } \\
\text { ensure safety } \\
\text { precaution to be } \\
\text { taken }\end{array}$ & Excellent \\
\hline
\end{tabular}




\section{References}

1. ILO: www.ilo.org/global/about-theilo/newsroom/features/WCMS_076282/lang-en/index.htmOECD (2008),

2. OECD Environmental Outlook, OECD, Paris, France.

3. Kleindorfer, P., Oktem, U., Pariyani, A. and Seider, W. (2012).Assessment of catastrophe risk and potential losses in industry.Computers \& Chemical Engineering, 47, pp.85-96.

4. Konstandinidou, M., Nivolianitou, Z., Markatos, N. And Kiranoudis, C. (2006). Statistical analysis of incidents reported in the Greek Petrochemical Industry for the period 1997â€"2003. Journal of Hazardous Materials, 135(1-3), pp.1-9.

5. Kossoris, M. (1939).A Statistical Approach to Accident Prevention.Journal of the American Statistical Association, 34(207), pp.524-532.

6. COOKE, W. and GAUTSCHI, F. (1981).OSHA, Plant Safety Programs, and Injury Reduction.Industrial Relations, 20(3), pp.245257.

7. Majid, M. and McCaffer, R. (1997).Assessment of Work Performance of Maintenance Contractors in Saudi Arabia.J. Manage. Eng., 13(5), pp.91-91.

8. Verbano, C., Venturini, K., (2013), "Managing Risks in SMEs: A Literature Review and Research Agenda", Journal of Technology Management \& Innovation 8(3), 1-17. 